\title{
蚪蚪提取物的酸导作 用*
}

\author{
生孝僡 王亞輝 曾弥白
}

(中国科学院实驗生物磔究所)

为了取材方便, 研究胚胎誘导一直都利 用成休动物的組辕。先检查它們的誘导作 用，从而进一步提取具有誘导作用的物稹。 䀢鼠的肝肚、腎脏、骨䯈，以及小牛胸腺、 鳮脴的抽精都能誘导属于一定区域的胚胎构 造, 它們的抽提物也具有相应的誘导专一性。 一般地就, 目前傾向于訩为誘使外胚层产生 神經組傤的物质是核醣核酸蛋白稹，使它产 生中肧层构造的是蛋白盾。但是关于前'管还 存在音不同的意見。虽然許多人都主张在 神經淁导中起作用的部分是核蛋白的蛋白部 分, 牛满江却詮为是这种物稹的核糖核酸部 分(结看 Brachet, 1960)。

这只是用成体組饿提取的結果，誰也不 知道，虽然作用相同，由成体中提取的是否 就是在胚胎中起作用的呢? 胚胎中的誘导物 是否可用同一方法提取呢? 我們曾經企图 用蛙的胚胎和蝗蚪作材料提取具有誘导作 用的物稹，籍以探討早期胚胎的誘导物貭的 作用, 以度在发育过程中这种物稹是否有稹 或量的改变。用的方法是 Cohen 氏錬需素 沉淀法**（Cohen 等, 1954), 用蝶缐的原腸 胚外胚层检查提取物的作用。用蝌蚪做材料 的几組有几点是很有兴趣的。

蝗蚪的与浆經鏈霹素沉淀、离心后，上 清液部分用酒棈沉腚, 得到的沉淀物 (TSP)
在外胚层中引起属于前头的神經組粒。值得 注意的是大量眼睛的出現，在 $15 / 20$ 的实驗 里都有眼睛及水晶体，而且多到一个外植块 里含有五、六个 (图 1)。同样值得注意的是 在两个外植块里除神經組織而外, 还有含卿 黄粒較多、細胞較大的內胚层腸道的出現。

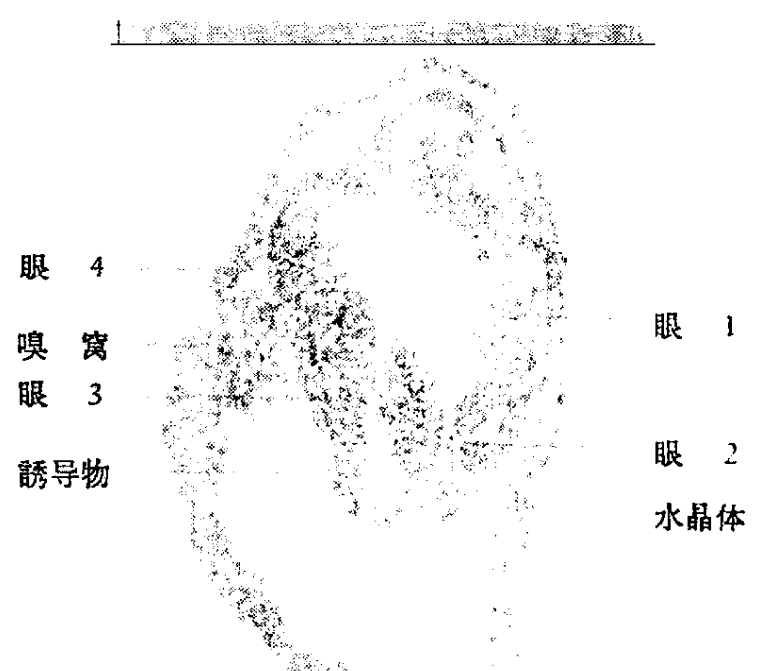

图 1 㮩导物誘导外胚层形成嗅窝和大量的眼睛, 其中一个带有水晶体

用 Mejbaum 氏 2,5-六垟基甲苯法和 Dische 氏二苯胺法分別测定 RNA 和 DNA， 上清液部分（TSP）均呈負反应。因此，这

* 这是实驗生物研究所分化专题組 1960 年进行的一 項集体工作的一部分。王亚輝和曾弥白分別貢貴生 化提取和胚胎实驗的工作。

** 鏈露素硫酸盐是华北淤厂出品, 实教用的最后浓度 是 $0.03 M$ 鏈震素硫酸盐。 
一部分不是核酸蛋白稹而是蛋白貭。这个实 䀫似乎指出不仅是核糖核酸蛋白，单純的 蛋白貭也可以誘导属于前头的神經組糡。在 誘导作用的研究中这类事实最近才有发現 (Kawakami, 196Q)。

鏈霜素沉淀物対含 $0.3 \mathrm{M} \mathrm{NaCl}$ 的嗍砂緩 冲液 ( $\mathrm{pH}$ 7.6) 透析后，部分不溶解 ( $\mathrm{Tpt} \mathrm{I}$ )。 溶解部分加椧酒精沉淀 (Tpt II)。Tpt I 和 Tpt II 苪部分都用作胚胎实驗。 $T p t$ II 部分 的作用和 TSP 部分差不多, 主要誘导属于 前头的神經組織和感覚器官， Tpt I 一組在 神經組纙的誘导力面和它們很一致，除此而 外，在 3 个例子里 (3/17) 还有少量的脊索細 胞，奇怪的是，它們关不是单独的一团或一 条，而是嵌在神經組織的壁里 (图 2)。

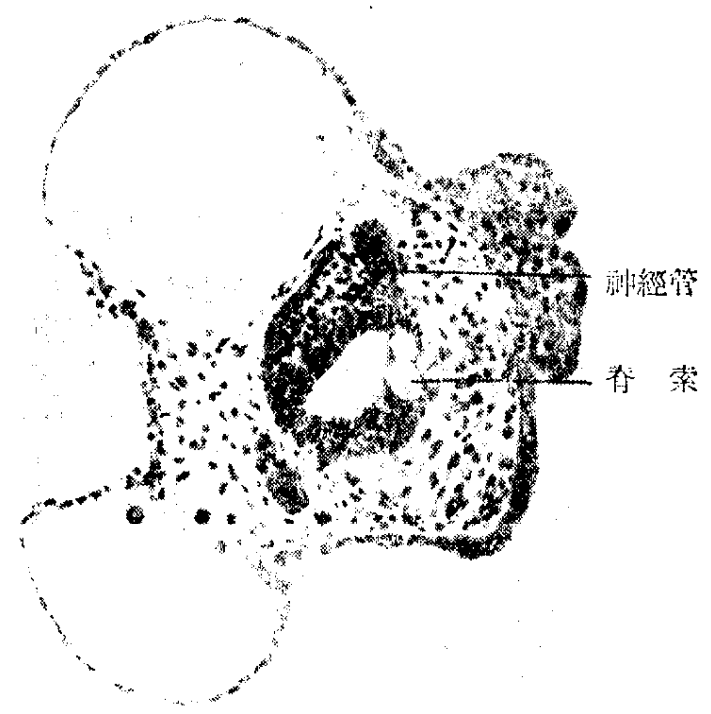

图 2 被誘导出来的脊甞欺在神經管的壁里

不論 Tpt I 或 Tpt II 部分还都誘导出 属于內胚层的构造，尽管这些构造出現的頻 率䉽不高(Tpt II 組 2/7; Tpt I 組 2/17)，
不能判断是消化道的那一部分 (图 3)。

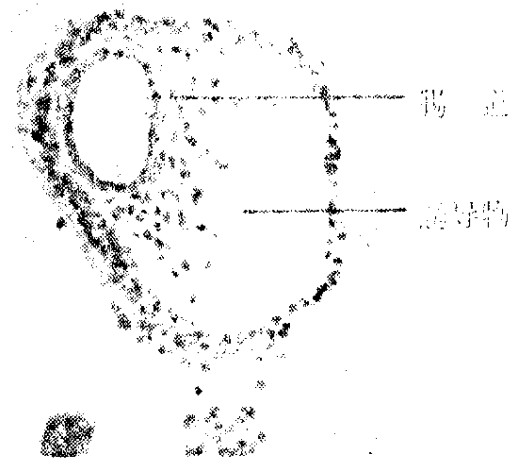

图 3 誘导物使外胚层产生內肧层的构造

經过日本学者的努力，內肧层誘导物盾 在成体組糡中的存在是絲毫没有疑問的了 （Takata \& Yamada，1960)。到現在我們只 知道, 在骨髓的例子里, 內肧层誘导往往是 和中胚层誘导同时出現的。我們的实驗証明 內胚层的誘导也可以和外胚层的誘导同时出 現，这对于內胚层誘导物稹在异源誘导体中 的存在状态提出了新的問題。

\section{丢 考 文 塥}

Brachet, J. 1960, The Biochemistry of Development. Pergamon press, London 1960.

Cohen, S., R. Levi-Montalcini \& V. Hamburger, 1954. A nerve growth-stimulating factor isolated from sarcomas 37 and 180. Proc. Natl. Acad. Sci. 40: $1014-1018$.

Takata, C. \& T. Yamada, 1960. Endodermal tissues developed from the isolated new ectoderm under the influence of guinea pig bone marrow. Embryologia, 5, 8-20.

Kawakami, I. \& S. Iyeiri, 1960. Separation of embryo inductive agents from non-ribonucleopratin fraction of Chick embryo extract. J. Expl. Zool., 145. 243250. 